\title{
Do processo de entrevista para a ferramenta InterVIU
}

\author{
Ricardo Rodrigues Nunes, Wallace Ugulino, Mariano Pimentel \\ Universidade Federal do Estado do Rio de Janeiro - UNIRIO \\ Av. Pasteur, 458, Urca-Cep: 22490040 - Rio de Janeiro, RJ, Brasil \\ \{ricardo.nunes, wallace.ugulino, Pimentel\}@uniriotec.br
}

\begin{abstract}
This paper presents the InterVIU's development, that used the CommunicaTEC's approach. A Collaboration Process is modeled to be performed through a computer tool, and an exploratory study is carried out aiming at identifying the problems in the process and the necessary changes to improve it. The changes in the process are reflected in mechanisms and implemented in the InterVIU tool. The main purposes of the InterVIU tool are: allow a specialist to be interviewed by a group and to reduce the number of questions without answers in the end of the interview.
\end{abstract}

Resumo. Neste artigo é apresentado o desenvolvimento da ferramenta InterVIU, que foi baseado na abordagem do projeto CommunicaTEC. Um processo de colaboração é modelado para ser executado por uma ferramenta computacional genérica e um estudo exploratório é conduzido para identificar os problemas no processo e as mudanças necessárias para aprimorá-lo para o meio computacional. As alterações no processo são refletidas em novos mecanismos implementados na ferramenta InterVIU. A principal característica da ferramenta é permitir um especialista ser entrevistado por um grupo, com o objetivo de obter menos perguntas sem resposta ao final da dinâmica.

\section{Sistemas para Colaboração}

Os Sistemas para Colaboração são compostos de diversas ferramentas, tais como, batepapo, correio-eletrônico, lista de discussão, fórum, agenda, questionários, tarefas, votação, conteúdos, etc. Estes sistemas se popularizaram e passaram a ser usados em situações para as quais não foram projetados.

Um grupo usa as ferramentas disponíveis num sistema para executar o trabalho em grupo. Desta forma, o processo de trabalho precisa ser modificado em função das ferramentas disponíveis e, algumas vezes, pode se tornar inadequado para o objetivo a ser alcançado. A inadequação ocorre porque as ferramentas não foram desenvolvidas especificamente para as tarefas do processo. Contudo, a cultura de uso destas ferramentas genéricas pode ser aproveitada para a especificação de novas ferramentas. Uma estratégia de desenvolvimento é implementar adaptações progressivamente nestas ferramentas, com base na análise dos processos desejados.

$\mathrm{Na}$ pesquisa apresentada neste artigo, são investigados os problemas que ocorrem no uso de ferramentas genéricas de bate-papo num determinado processo de entrevista. Também são estudados e propostos mecanismos que são desenvolvidos em novas versões da ferramenta para resolver alguns dos problemas identificados. 
A pesquisa faz parte do projeto CommunicaTEC [Pimentel 2006] [Ugulino et al. 2008], onde são investigados o uso e o desenvolvimento de tecnologias de comunicação para educação e colaboração. Um dos objetivos do projeto é investigar processos de colaboração visando adaptar ferramentas genéricas para a aplicação de técnicas específicas de trabalho em grupo - esta abordagem é descrita na Seção 2. Na Seção 3, um processo de entrevista é caracterizado. Algumas ferramentas de entrevista são apresentadas na Seção 4. Um estudo exploratório é detalhado na seção 5, onde foram identificados problemas na realização através de uma ferramenta de bate-papo genérica. Na seção 6, são descritos o desenvolvimento e as características da ferramenta InterVIU: uma ferramenta de bate-papo específica, adaptada para dar suporte ao processo de entrevista apresentado nesta pesquisa. Conclusão e trabalhos futuros estão na Seção 7.

\section{Projeto CommunicaTEC}

O objetivo do projeto CommunicaTEC é pesquisar e desenvolver ferramentas para apoiar a aplicação de uma técnica de trabalho em grupo. A técnica é modelada como um fluxo de ações, denominado processo-da-técnica. Através de estudos exploratórios, investigam-se problemas que ocorrem ao aplicar determinada técnica através de uma ferramenta computacional genérica. A partir da análise dos resultados obtidos nos estudos exploratórios, o processo-da-técnica é remodelado com o objetivo de diminuir a ocorrência dos problemas mais relevantes. Para apoiar o novo processo, são implementados mecanismos que resultam numa ferramenta específica para a técnica (Figura 1).

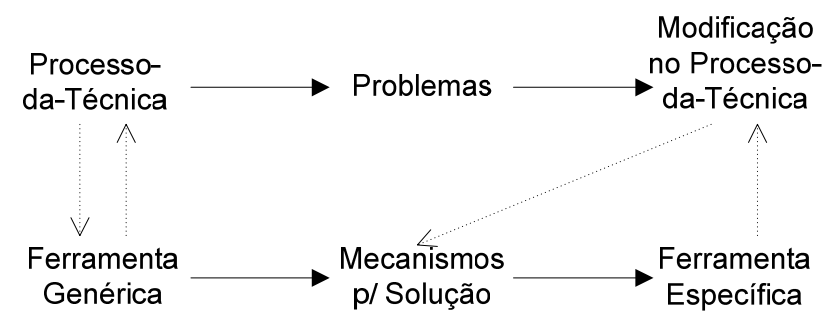

Figura 1. CommunicaTEC: Abordagem para o desenvolvimento de ferramentas específicas

Um processo de colaboração é composto de diversas tarefas organizadas em disciplinas. Cada disciplina é descrita em fluxos de tarefas para alcançar objetivos e produzir artefatos. Uma tarefa pode ser executada pela aplicação de uma técnica de trabalho em grupo apoiada por uma ferramenta computacional.

A partir da modelagem dos processos de colaboração e de estudos exploratórios, são identificadas modificações necessárias no processo e na ferramenta para a realização no novo processo. A pesquisa consiste em tentar adequar as ferramentas computacionais para a aplicação de técnicas específicas de trabalho em grupo, bem como adequar as técnicas para que sejam mediadas pelo computador (Figura 2). 


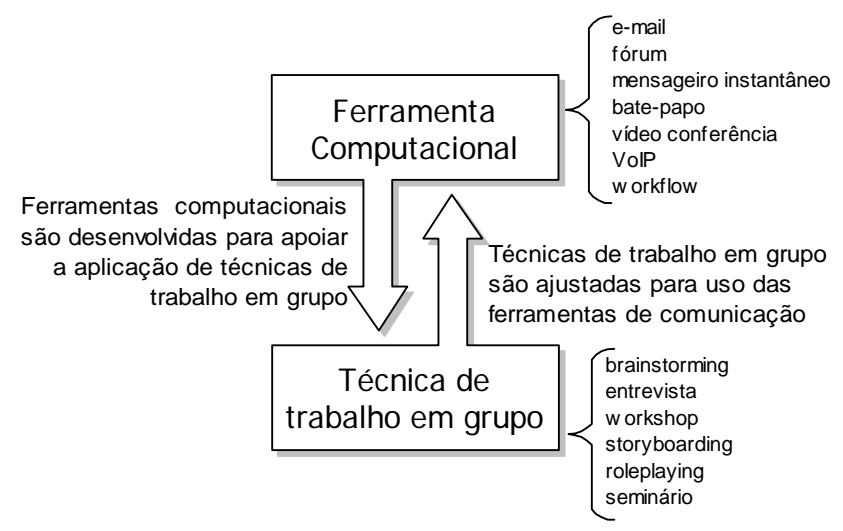

Figura 2. CommunicaTEC: ferramentas específicas para a aplicação de técnica de trabalho em grupo

Na Seção 3 é apresentada a pesquisa sobre o processo de entrevista em que foram identificados problemas na realização através da ferramenta de bate-papo genérica.

\section{Processo de entrevista}

A Entrevista é uma das mais conhecidas técnicas de trabalho em grupo [Minicucci 2001]. É uma situação em que uma ou mais pessoas formulam perguntas ou apresentam questões a um ou vários indivíduos. Em geral, a entrevista faz abordagem de um tema, onde um especialista é interrogado. É uma conversa com personagem notável ou portador de conhecimentos ou informações de interesse de um público [Lage 2002]. Uma entrevista permite reduzir os isolamentos grupais, individuais e sociais. Constitui sempre um meio cujo fim é o inter-relacionamento humano [Medina 2002].

A técnica entrevista é usada em diversas áreas do conhecimento. Entrevistas são aplicadas na psicologia, na medicina, na comunicação, na sociologia, na saúde, na administração, na educação [Nunes 2008] etc. Há entrevista fenomenológica, motivacional, de ajuda, de seleção, para pesquisa científica, reflexiva, diagnóstica etc. $\mathrm{O}$ presente estudo foi focado no processo da técnica de entrevista de muitos para um. A entrevista é não-moderada para grupos de até 30 participantes.

O processo é dividido em três disciplinas: 1 . Pré-Entrevista, que compreende as atividades de convite e preparação do entrevistado e entrevistadores; 2. Entrevista, que é a sessão de entrevista propriamente dita; 3. Pós-Entrevista, constituída das atividades desde a síntese do conteúdo até a publicação do resultado aos participantes (Figura 3).

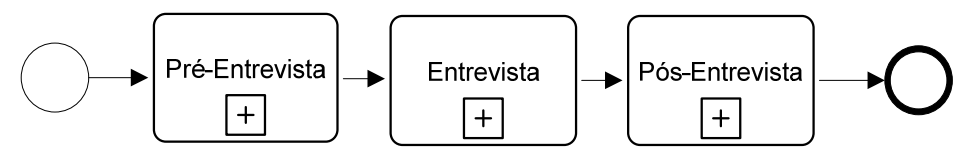

Figura 3. O processo de entrevista

A execução desse processo de entrevista tem como objetivo possibilitar que os participantes questionem um especialista (o entrevistado) sobre um tema. No processo, estão presentes os papéis de mediador, entrevistado e entrevistador, cada um com diferentes responsabilidades. O mediador do processo tem como tarefas da disciplina Pré-Entrevista: convidar entrevistado e entrevistadores e preparar o roteiro para o entrevistado (possíveis perguntas e perfil dos entrevistadores) e para os entrevistadores 
(constituído de conteúdos básicos para prepará-los sobre o determinado tema). Os entrevistadores e o entrevistado prepararam-se para a entrevista.

Na disciplina Entrevista, para a realização da sessão, é usada uma ferramenta computacional. O mediador apresenta o entrevistado, inicia e finaliza a sessão. Os entrevistadores podem conversar com o entrevistado e entre si durante a sessão, como forma de socialização. As perguntas são enviadas diretamente dos entrevistadores para o entrevistado.

Na disciplina Pós-Entrevista, as tarefas são executadas pelo mediador, que envia uma mensagem de divulgação a todos os participantes depois de produzir e publicar uma síntese da entrevista. Na Figura 4 é representado, detalhadamente, todo o processo de entrevista explicado.
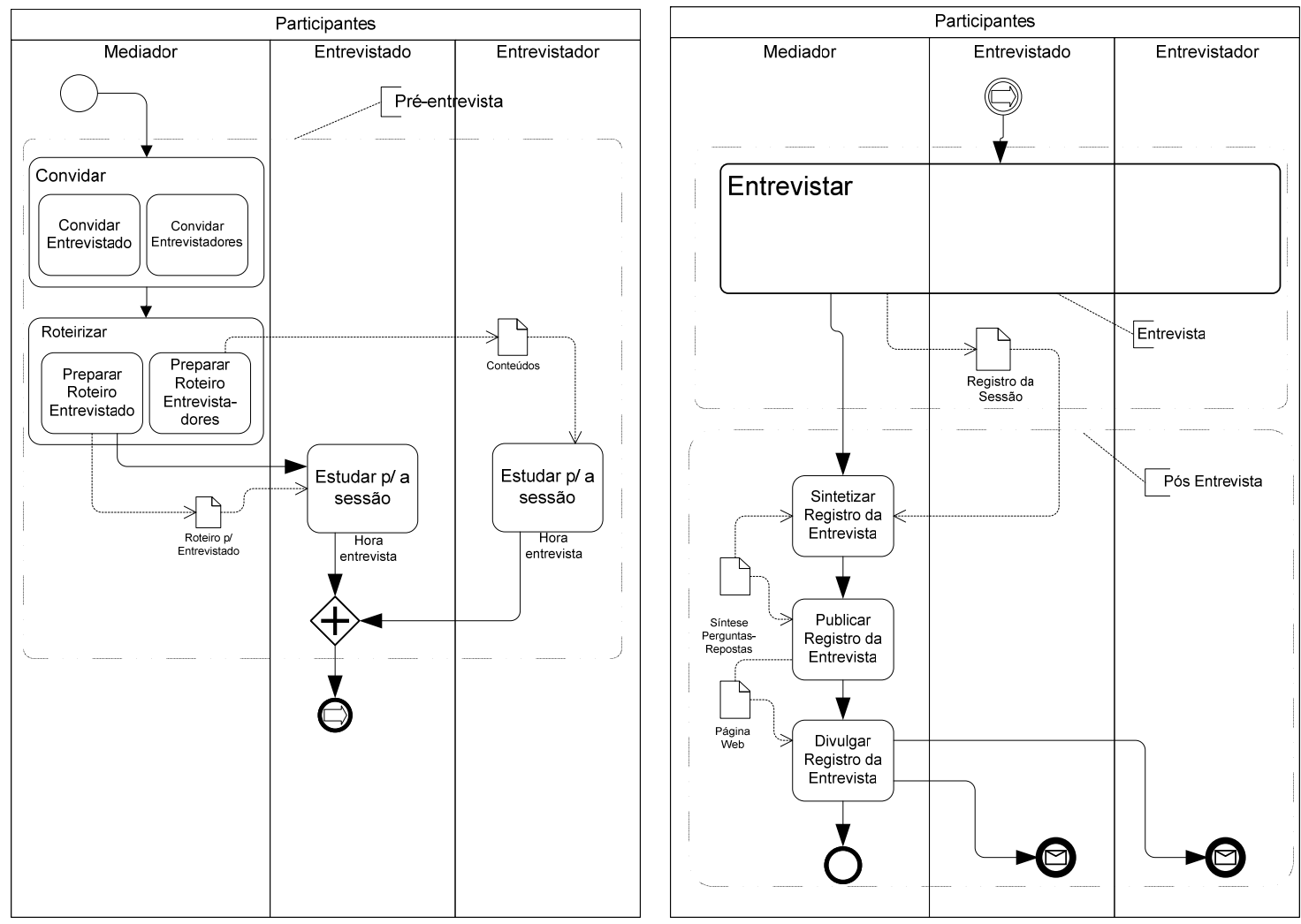

Figura 4. O processo de entrevista

Do processo de entrevista, foi escolhido como objeto de estudo a tarefa "Entrevistar" da disciplina Entrevista. O estudo permitiu descobrir problemas ao aplicar a técnica de entrevista pela internet apoiada por uma ferramenta genérica de bate-papo textual. O processo da técnica foi revisto e modificado para tentar diminuir a ocorrência de alguns problemas existentes, ligados à estruturação da comunicação, quando realizada por meio computacional. A realização por bate-papo textual na internet possibilita o acesso mais facilitado dos participantes, por exigir poucos recursos computacionais e de banda de internet. Possibilita ainda que os participantes estejam distribuídos geograficamente. Contudo, a comunicação textual via bate-papo impõe restrições à técnica de entrevista. 


\section{Ferramentas de entrevistas}

A internet vem se firmando como um importante meio para a realização e difusão de entrevistas através de textos, áudios ou vídeos. Através de computadores nas residências, cyber-cafés e lan-houses, as pessoas têm a possibilidade de acessar a internet e participar de programas de entrevista. O bate-papo é a ferramenta mais usada para promover uma entrevista na internet, porém é difícil acompanhar as entrevistas através do bate-papo [Pessoa 2002]. Uma comparação das ferramentas de entrevistas dos principais portais de internet brasileiros e a análise de uma ferramenta específica, chamada Entrevist@ são apresentadas nas seções a seguir.

\subsection{Ferramentas de entrevista dos principais portais brasileiros}

Existem diversas ferramentas de bate-papo, que são utilizadas para a realização de entrevistas. A seguir, destacam-se as ferramentas dos principais portais brasileiros: UOL, Terra, IG e Globo (Figura 5).

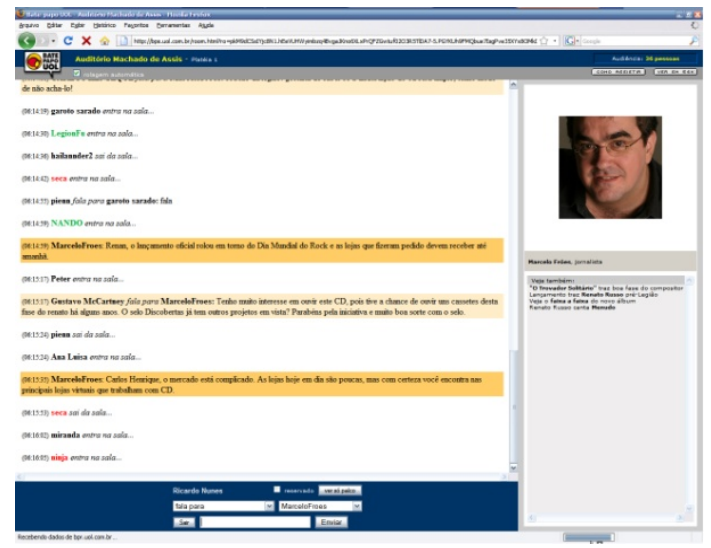

(UOL Bate-papo com Convidados)

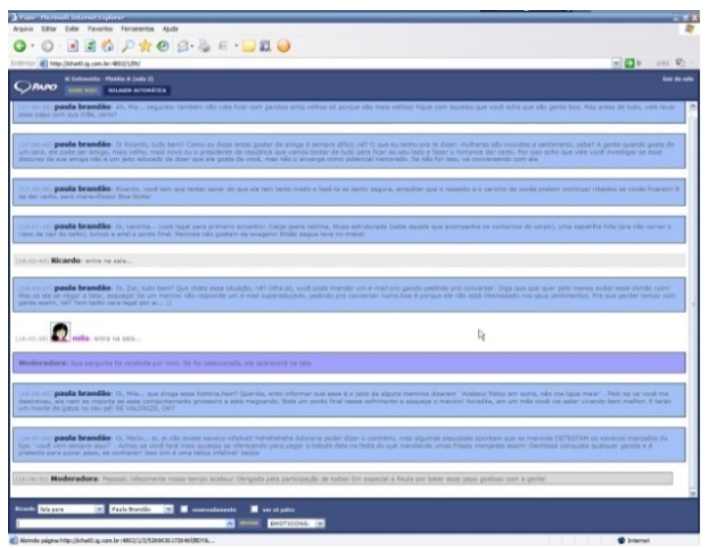

(IG Papo Agenda)

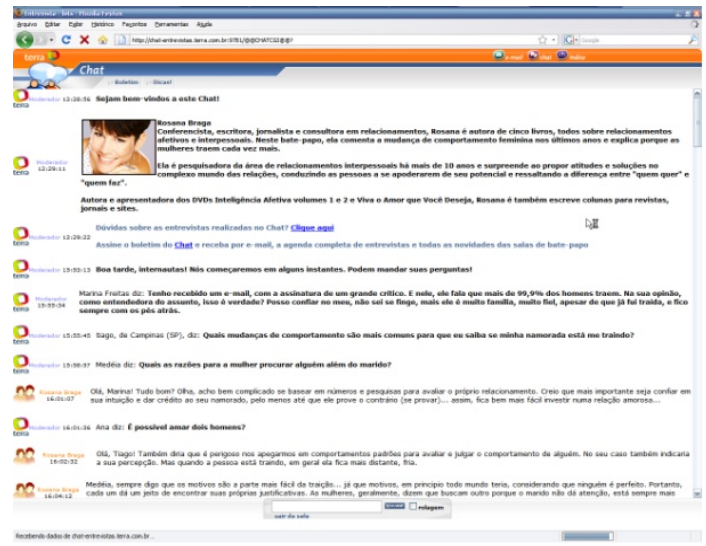

(Terra Chat Entrevistas)

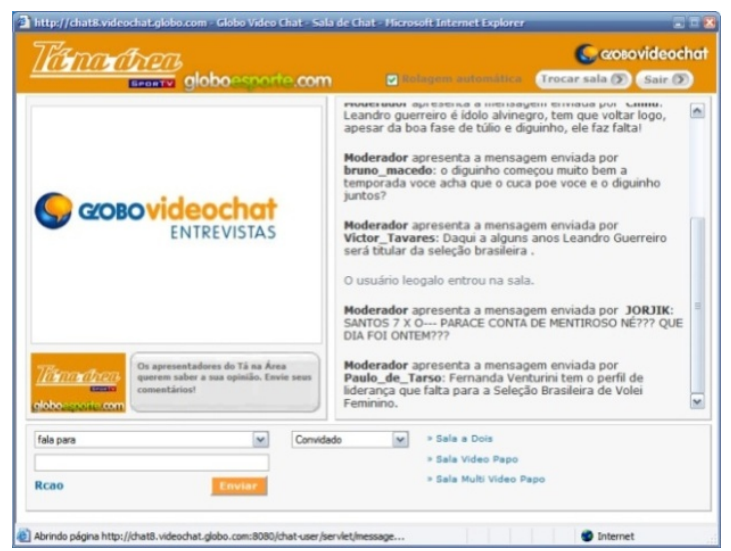

(Globo VideoChat)

Figura 5. Ferramentas de entrevistas dos principais portais brasileiros

As ferramentas de bate-papo usadas para entrevistas nos principais portais brasileiros foram analisadas usando o framework conceitual 3C do domínio de ferramentas de comunicação Síncrona [Pimentel et al. 2006]. O resultado da análise das ferramentas de entrevistas é apresentado na Tabela 1. 
Tabela 1. Análise das ferramentas de entrevista de portais brasileiros

\begin{tabular}{|c|c|c|c|c|c|}
\hline \multicolumn{2}{|c|}{$\begin{array}{l}\text { Elementos } 3 \mathrm{C} \\
\text { para análise }\end{array}$} & \multirow{2}{*}{$\begin{array}{l}\text { UOL Batepapo } \\
\text { com } \\
\text { Convidados } \\
\text { texto, vídeo do } \\
\text { entrevistado (só para } \\
\text { assinantes) }\end{array}$} & \multirow{2}{*}{$\begin{array}{l}\text { Terra Chat } \\
\text { Entrevistas } \\
\text { Texto, vídeo do } \\
\text { entrevistado }\end{array}$} & \multirow{2}{*}{$\begin{array}{l}\text { I G } \\
\text { Papo Agenda } \\
\text { Texto, vídeo do entrevistado }\end{array}$} & \multirow{2}{*}{$\begin{array}{l}\text { Globo } \\
\text { Videochat } \\
\text { Texto, vídeo ou } \\
\text { áudio do } \\
\text { entrevistado }\end{array}$} \\
\hline \multirow{5}{*}{ 空 } & Linguagem & & & & \\
\hline & Transmissão & $\begin{array}{l}\text { Pontual, contínua do } \\
\text { entrevistado }\end{array}$ & $\begin{array}{l}\text { Pontual, contínua do } \\
\text { entrevistado }\end{array}$ & pontual & $\begin{array}{l}\text { Pontual, contínua do } \\
\text { entrevistado }\end{array}$ \\
\hline & $\begin{array}{l}\text { Tamanho e } \\
\text { qualidade }\end{array}$ & sem limite & sem limite & sem limite & Sem limite \\
\hline & $\begin{array}{l}\text { Estruturação do } \\
\text { discurso }\end{array}$ & linear & linear & linear & linear \\
\hline & Categorização & $\begin{array}{l}\text { tipo de fala, } \\
\text { mensagem moderador, } \\
\text { respostas do } \\
\text { entrevistado }\end{array}$ & $\begin{array}{l}\text { mensagem moderador, } \\
\text { respostas do entrevistado }\end{array}$ & $\begin{array}{l}\text { tipo de fala, tipo de emoção, } \\
\text { mensagem moderador, } \\
\text { respostas do entrevistado }\end{array}$ & $\begin{array}{l}\text { mensagem } \\
\text { moderador, } \\
\text { respostas do } \\
\text { entrevistado } \\
\end{array}$ \\
\hline \multirow{12}{*}{ ن } & Tópico & $\operatorname{sim}$ & $\operatorname{sim}$ & $\operatorname{sim}$ & $\operatorname{sim}$ \\
\hline & Sessão & $\operatorname{sim}$ & $\operatorname{sim}$ & $\operatorname{sim}$ & $\operatorname{sim}$ \\
\hline & Acesso & $\begin{array}{l}\text { Limite de } 30 \text { por sala, } \\
10 \text { vagas reservadas } \\
\text { para assinantes }\end{array}$ & $\begin{array}{l}\text { Limite de } 2 \text { mil pessoas } \\
\text { simultâneas }\end{array}$ & irrestrito & irrestrito \\
\hline & Presença & $\begin{array}{l}\text { entrevistado, } \\
\text { entrevistadores }\end{array}$ & não lista os participantes & entrevistados, entrevistadores & $\begin{array}{l}\text { Entrevistado, } \\
\text { moderador, } \\
\text { entrevistadores }\end{array}$ \\
\hline & Disponibilidade & online (todos na sala) & online (todos na sala ) & online (todos na sala) & $\begin{array}{l}\text { online (todos na } \\
\text { sala) }\end{array}$ \\
\hline & Papéis & $\begin{array}{l}\text { entrevistador, } \\
\text { entrevistado, } \\
\text { moderador }\end{array}$ & $\begin{array}{l}\text { entrevistador, } \\
\text { entrevistado, moderador }\end{array}$ & $\begin{array}{l}\text { entrevistador, moderador, } \\
\text { entrevistado }\end{array}$ & $\begin{array}{l}\text { entrevistador, } \\
\text { convidado, } \\
\text { moderador }\end{array}$ \\
\hline & Posse da palavra & moderada & moderada & moderada & moderada \\
\hline & Freqüência & sem limitação & sem limitação & sem limitação & sem limitação \\
\hline & Visibilidade & Pública, privada & Pública & Pública & Pública \\
\hline & Endereçamento & $\begin{array}{l}\text { entrevistador para } \\
\text { entrevistado; } \\
\text { entrevistador para } \\
\text { entrevistador }\end{array}$ & $\begin{array}{l}\text { entrevistador para } \\
\text { entrevistado }\end{array}$ & $\begin{array}{l}\text { entrevistador para } \\
\text { entrevistado; entrevistador } \\
\text { para entrevistador }\end{array}$ & $\begin{array}{l}\text { entrevistador para } \\
\text { entrevistado, } \\
\text { entrevistador para } \\
\text { entrevistador }\end{array}$ \\
\hline & $\begin{array}{l}\text { I ndicação do } \\
\text { turno-em- } \\
\text { desenvolvimento }\end{array}$ & $\begin{array}{l}\text { digitação do } \\
\text { entrevistado (através } \\
\text { do vídeo), sem } \\
\text { indicações dos outros } \\
\text { participantes }\end{array}$ & sem indicações & sem indicações & $\begin{array}{l}\text { digitação do } \\
\text { entrevistado (através } \\
\text { do vídeo), sem } \\
\text { indicação dos outros } \\
\text { participantes }\end{array}$ \\
\hline & Avaliação & não & não & não & não \\
\hline \multirow{3}{*}{\begin{tabular}{l}
0 \\
\multirow{2}{2}{} \\
0 \\
0 \\
0 \\
0 \\
0 \\
0 \\
0
\end{tabular}} & Registro & $\begin{array}{l}\text { repositório editado de } \\
\text { entrevistas anteriores; } \\
\text { registra: hora, emissor } \\
\text { e conteúdo da } \\
\text { mensagem }\end{array}$ & $\begin{array}{l}\text { repositório editado de } \\
\text { entrevistas anteriores; } \\
\text { registra: hora, emissor, } \\
\text { destinatário, categoria e } \\
\text { conteúdo da mensagem; }\end{array}$ & $\begin{array}{l}\text { repositório editado de } \\
\text { entrevistas anteriores; } \\
\text { registra: hora, emissor, } \\
\text { destinatário, categoria e } \\
\text { conteúdo da mensagem }\end{array}$ & $\begin{array}{l}\text { repositório editado } \\
\text { de entrevistas } \\
\text { anteriores; } \\
\text { registra: emissor, } \\
\text { destinatário, tipo-de- } \\
\text { fala e conteúdo da } \\
\text { mensagem }\end{array}$ \\
\hline & $\begin{array}{l}\text { Configuração do } \\
\text { espaço }\end{array}$ & $\begin{array}{l}\text { janela única, com } \\
\text { destaque para as } \\
\text { mensagens de } \\
\text { mediador e do } \\
\text { entrevistado }\end{array}$ & $\begin{array}{l}\text { janela única, com } \\
\text { destaque para as } \\
\text { mensagens de mediador } \\
\text { e do entrevistado }\end{array}$ & $\begin{array}{l}\text { janela única, com destaque } \\
\text { para as mensagens de } \\
\text { mediador e do entrevistado }\end{array}$ & $\begin{array}{l}\text { janela única, com } \\
\text { destaque para as } \\
\text { mensagens de } \\
\text { mediador e do } \\
\text { entrevistado }\end{array}$ \\
\hline & $\begin{array}{l}\text { Mensagens } \\
\text { preconcebidas }\end{array}$ & não & não & não & não \\
\hline
\end{tabular}




\subsection{Ferramenta Entrevist@}

Existe na literatura para sistemas colaborativos uma ferramenta específica para entrevista: a ferramenta Entrevist@. Na ferramenta Entrevist@ [Pessoa 2002], existe uma região separada para as respostas do entrevistado. O objetivo é não permitir que as mensagens dos entrevistadores se misturem com a dos entrevistados. Na ferramenta, as respostas do entrevistado são precedidas pelas perguntas do entrevistador. Dessa forma, os textos dos entrevistadores e entrevistado não se misturam e diminui a dificuldade de se relacionar a resposta à pergunta. Esta versão da ferramenta Entrevist@ foi desenvolvida para resolver dois dos problemas identificados no uso de ferramentas semelhantes para entrevistas. A seguir são listados os problemas encontrados [Pessoa 2002].

- os textos do entrevistado e o dos entrevistadores se misturam;

- algumas vezes é difícil relacionar a resposta a sua pergunta;

- é difícil para o entrevistado responder as perguntas de vários entrevistadores, na ausência de um moderador para filtrar as perguntas;

- os participantes ficam desconfiados da identidade do entrevistado, na ausência de um vídeo;

- às vezes parece que o entrevistado demora a responder, quando está digitando frases longas.

Para que os participantes encontrem as mensagens do entrevistado, na interface da Entrevist@ existem duas áreas: uma para as mensagens e perguntas dos entrevistadores e outra para o pareamento pergunta/resposta. Para tentar resolver o problema de relacionar a resposta com sua respectiva pergunta, a ferramenta tem uma funcionalidade onde o entrevistado ao responder, clica sobre a pergunta para abrir uma janela e digitar sua resposta. Assim, é possível apresentar o par pergunta/resposta.

\section{Estudo exploratório com ferramenta genérica de bate-papo}

Em um estudo exploratório, foi aplicada uma dinâmica de entrevista usando uma ferramenta genérica de bate-papo com alunos de graduação e pós-graduação em informática que eram interessados no tema da entrevista proposta. Os participantes da entrevista foram convidados através de mala-direta por e-mail. Para preparar os entrevistadores, os participantes foram orientados a assistir um vídeo, criado pelo grupo de pesquisa do entrevistado.

Foi usada a técnica de entrevista não-moderada. O papel do moderador foi substituído pelo mediador para apresentar o entrevistado, iniciar e encerrar a sessão de entrevista. As perguntas foram enviadas pelos entrevistadores diretamente ao entrevistado e todos os participantes puderam conversar entre si. A sessão de entrevista durou aproximadamente 1 hora e participaram 12 pessoas. Foi feita uma síntese da entrevista com os pares perguntas e respostas e as mensagens de socialização. A síntese foi disponibilizada em uma página na web.

Para investigar os problemas que ocorrem com o uso do bate-papo na realização de entrevistas, foram coletados dados através de questionários e do registros de mensagens da sessão. A análise dos dados possibilitou identificar alguns problemas:

- pergunta-sem-resposta: de todas as perguntas feitas durante a sessão de entrevista, aproximadamente $16 \%$ das perguntas ficaram sem resposta. Este 
problema pode ocorrer pelo fato de existirem muitas mensagens em uma sessão, causando assim, uma sobrecarga de mensagens;

- dificuldade de parear pergunta-resposta: foi difícil identificar qual é a pergunta, que de fato, o entrevistado estava respondendo. Este problema está relacionado à desordem nos turnos. No bate-papo, um turno equivale a uma mensagem. Em uma conversa face-a-face, espera-se que o turno seguinte esteja relacionado com o anterior, dando sequência à conversação, porém em um bate-papo isso não ocorre, pois os interlocutores muitas vezes iniciam a produção dos turnos de maneira concomitante;

- dificuldade de identificar perguntas e respostas: muitas vezes durante a sessão foi difícil identificar o que era pergunta, o que era resposta e o que era mensagem de socialização. Este problema pode ocorrer devido às perguntas e as respostas estarem misturadas com as mensagens;

- sobrecarga de perguntas: algumas vezes, durante a entrevista, foram enviadas várias perguntas num curto intervalo de tempo, sem tempo hábil para que o entrevistado pudesse respondê-las. Este problema pode ocorrer por existirem muitos entrevistadores fazendo perguntas para um entrevistado apenas;

- inversão de papéis: quando perguntas eram enviadas e nenhuma resposta era dada durante um tempo, alguns participantes respondiam no lugar do entrevistado. A demora na resposta criou uma ansiedade nos participantes que ficam sem saber se o entrevistado irá responder ou não uma pergunta. A demora do entrevistado pode ter ocorrido por estar formulando e digitando a resposta, ou estar lendo o histórico da entrevista para ver se havia pulado alguma pergunta. Este problema ocorre por causa da simetria do bate-papo (participantes têm as mesmas funcionalidades disponíveis na ferramenta). Em uma entrevista, numa ferramenta de bate-papo genérica, qualquer um pode responder uma pergunta;

Para tentar resolver dois dos problemas encontrados na realização do estudo exploratório, uma adaptação no processo da técnica de entrevista foi proposta, tal como, o desenvolvimento de uma ferramenta específica, chamada InterVIU, para apoiar a aplicação da técnica adaptada.

\section{Adaptação no processo de entrevista e o desenvolvimento do InterVIU}

Para tentar resolver dois dos problemas encontrados na realização do estudo exploratório, pergunta-sem-resposta e a dificuldade de parear pergunta-resposta, uma adaptação no processo da técnica de entrevista, aplicada na tarefa "Entrevistar", foi proposta. A ferramenta InterVIU é derivada do estudo exploratório para dar suporte a aplicação do processo de entrevista modificado.

\subsection{Adaptação no processo de entrevista}

O fluxo de ações do processo da técnica utilizada no estudo exploratório é representado na Figura 6a. O novo fluxo de ações proposto para a técnica é representado na Figura 6b. A ferramenta InterVIU foi desenvolvida especificamente para apoiar a aplicação da técnica com o novo fluxo. Neste caso, o fluxo da técnica utilizada foi expandido e desmembrado em ações não discriminadas anteriormente. Discriminar as ações de uma tarefa é uma tentativa de permitir ao participante dedicar-se mais a uma ou outra de acordo com a demanda. 

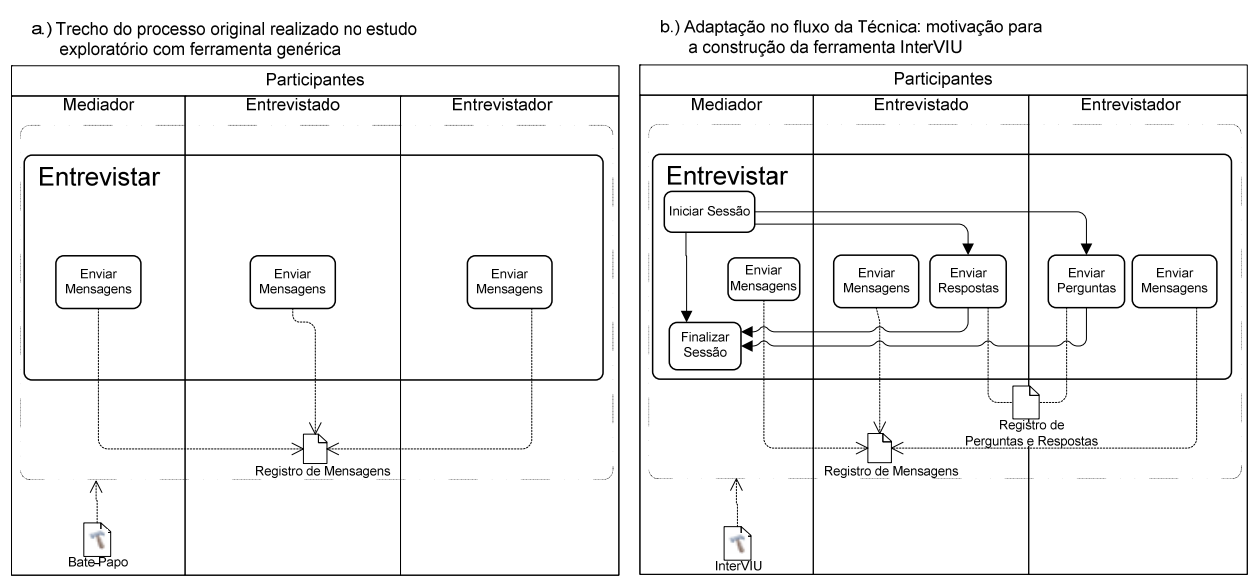

Figura 6. Proposta de adaptação do fluxo de ações do processo de entrevista

No trecho de processo, representado na Figura 6a, entrevistado e entrevistadores enviam mensagens no bate-papo, e o entrevistado tenta identificar o que é pergunta e respondê-la. No trecho do processo proposto, Figura 6b, entrevistadores possuem tarefas distintas: bate-papo para socialização e pergunta. Para o entrevistado, também existem duas tarefas distintas: responder perguntas e enviar mensagens de socialização no bate-papo. Tanto no caso de entrevistado como no caso de entrevistadores, as duas tarefas podem ser realizadas de forma concomitante. Espera-se assim, diminuir o número de perguntas-sem-resposta e facilitar a identificação dos pares perguntaresposta.

\subsection{Histórico do desenvolvimento do InterVIU}

Em entrevistas realizadas em ferramentas genéricas de bate-papo, é difícil acompanhar as mensagens do entrevistador. Visando resolver este problema, nas ferramentas de entrevistas comerciais, foram definidos três papéis (entrevistado, moderador e entrevistador). As mensagens são filtradas pelo moderador, que escolhe as perguntas que considera relevantes ao tema da entrevista. As perguntas aceitas pelo moderador e as mensagens do entrevistado aparecem destacadas. Mesmo assim, é difícil identificar qual pergunta o entrevistado está respondendo.

A ferramenta Entrevist@ [Pessoa 2002], foi desenvolvida para tentar resolver o problema de identificar qual pergunta o entrevistado está respondendo. A ferramenta tem uma funcionalidade onde o entrevistado ao responder uma pergunta, clica sobre ela para abrir uma janela onde pode digitar sua resposta. Para facilitar que os participantes encontrem as mensagens do entrevistado, a interface da Entrevist@ apresenta duas áreas, uma com as mensagens e perguntas dos entrevistadores e outra para o pareamento pergunta/resposta.

A ferramenta InterVIU é uma evolução das ferramentas de entrevista, numa tentativa de adaptar a ferramenta de bate-papo para realizar o processo de entrevista. $\mathrm{Na}$ ferramenta InterVIU são mantidas algumas funcionalidades encontradas nas principais ferramentas comerciais e na Entrevist@ e propõe-se um novo mecanismo para tentar resolver um dos problemas identificados no estudo exploratório (pergunta-semresposta). Na Figura 7 é representada a evolução das ferramentas visando resolver os problemas na utilização do bate-papo para a realização de entrevistas. 


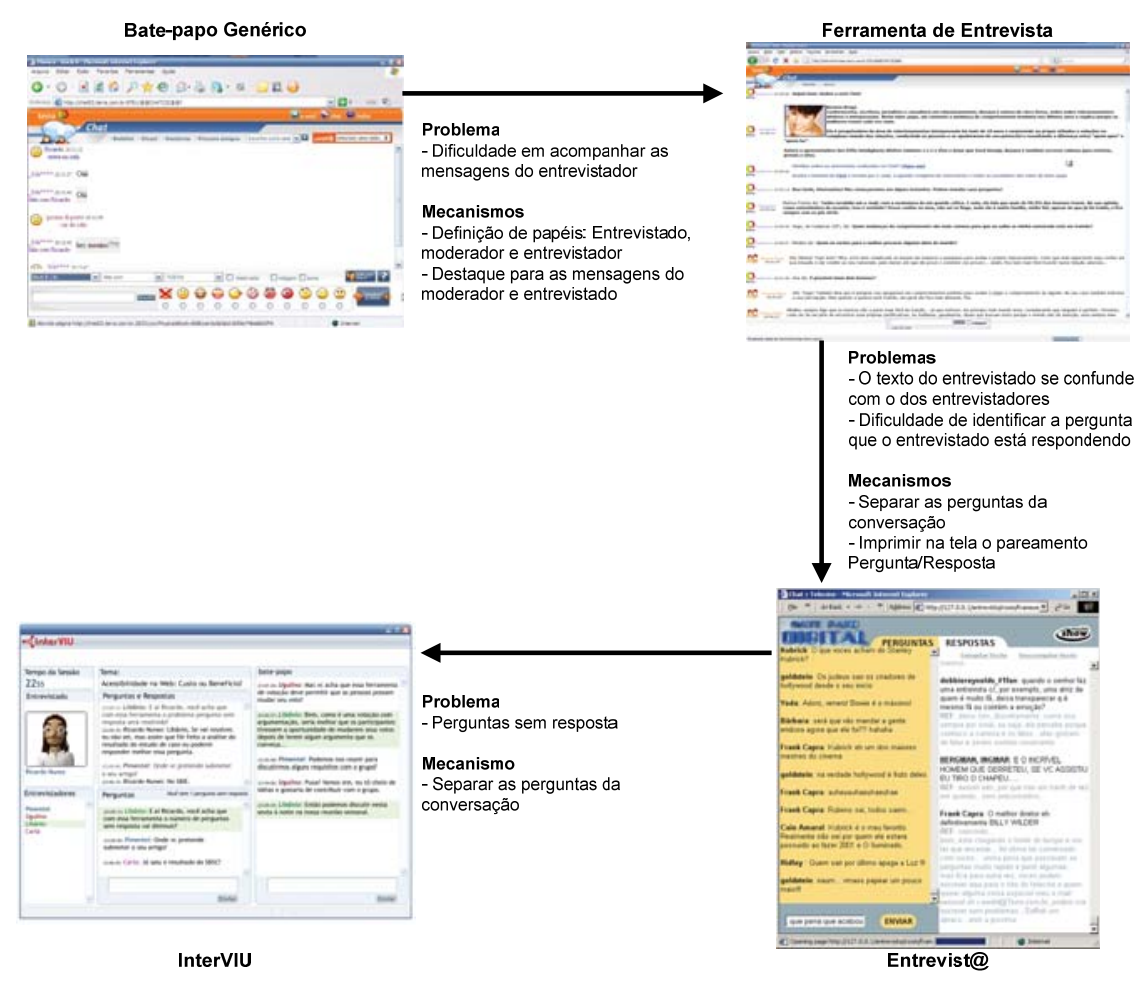

Figura 7. Evolução do desenvolvimento da ferramenta InterVIU

A ferramenta InterVIU foi desenvolvida para atender grupos médios, de até 30 participantes, com o objetivo de diminuir o número de perguntas que ficam sem respostas em uma sessão de entrevista. O resultado ideal é que só restem perguntas-semrespostas quando o entrevistado, por algum motivo, não queira responder a pergunta, seja por já ter respondido uma pergunta parecida, pelo fato da pergunta não ser sobre o tema da entrevista ou um outro motivo qualquer.

No InterVIU, são definidos três papéis na realização de uma entrevista: mediador, entrevistador e entrevistado. A ferramenta apresenta uma visão para cada tipo de papel, onde existem funcionalidades importantes para cada um dos papéis.

Na visão do entrevistador, na área das perguntas, existe uma caixa de texto, onde devem ser digitadas as perguntas. Há uma funcionalidade que indica o número de perguntas enviadas pelo entrevistador que ainda não foram respondidas pelo entrevistado. Existe também, uma área que apresenta o pareamento pergunta/resposta da sessão da entrevista. Essa funcionalidade foi proposta na ferramenta Entrevist@ para tentar resolver o problema do texto do entrevistado se confundir com o texto dos entrevistadores. Como a ferramenta Entrevist@ foi desenvolvida para um trabalho final de graduação e não houve uma avaliação sistematizada, optou-se por implementar essa funcionalidade para poder ser verificado científicamente se a proposta ajuda a resolver esse problema.

Na área destinada às mensagens genéricas da sessão de bate-papo existe uma caixa de texto onde devem ser digitadas essas mensagens. Essa área permite que os participantes possam trocar mensagens entre si. A seguir, é apresentada a tela da ferramenta InterVIU na visão do entrevistador, onde são apresentadas as áreas das mensagens, das perguntas e das respostas. Os entrevistadores podem trocar mensagens entre si, enviar perguntas e ver o conjunto de perguntas e respostas (Figura 8). 


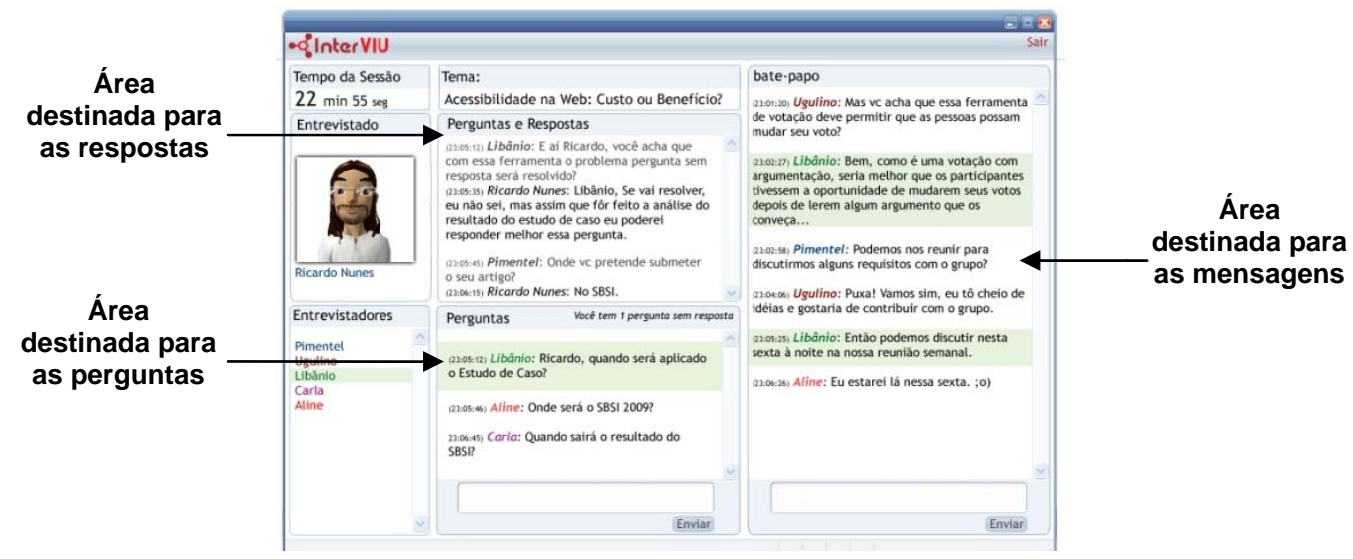

Figura 8. Ferramenta InterVIU na visão do entrevistador

A solução adotada para resolver o problema pergunta-sem-resposta consiste em apresentar uma área destinada às pergunta que permite ao entrevistado identificar, de forma mais simples, as perguntas que ainda não foram respondidas. $\mathrm{O}$ entrevistado pode clicar em qual pergunta ele quer responder, abrindo um área onde ele digita sua resposta (Figura 9).

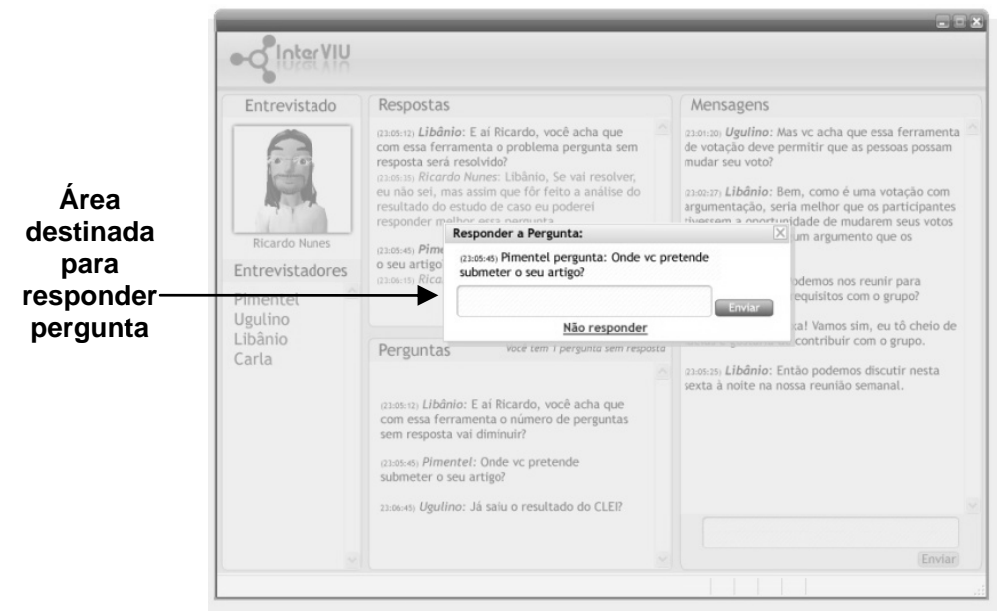

Figura 9. Visão do entrevistado ao clicar na pergunta que quer responder

O mediador, através da interface, pode iniciar e encerrar a sessão da entrevista. O mediador também tem a possibilidade de enviar, ao final de uma sessão de entrevista, o conjunto de perguntas e respostas para o e-mail dos participantes (síntese da entrevista).

A seguir é apresentado como trabalho futuro o projeto do estudo de caso que visa avaliar a ferramenta para confirmar ou refutar a hipótese de que usando o InterVIU, ao final de uma sessão de entrevista, haverá menos perguntas-sem-resposta e a possibilidade, através de outras pesquisas no futuro, do desenvolvimento de um portal de entrevistas.

\section{Conclusão e trabalhos futuros}

Neste artigo é apresentado o desenvolvimento da ferramenta InterVIU, que foi baseado na abordagem do projeto CommunicaTEC. Os estudos realizados indicam que a abordagem tem se mostrado útil para identificar os problemas no processo, modificá-lo 
e especificar e desenvolver mecanismos de apoio ao processo que são implementados em nova versão da ferramenta. Através desta abordagem, tem sido possível desenvolver ferramentas mais adequadas para colaboração.

O projeto do estudo de caso consiste em aplicar duas dinâmicas de entrevista com um especialista em uma disciplina da graduação da Universidade Federal do Estado do Rio de Janeiro - UNIRIO. A turma será dividida em dois grupos, onde os participantes serão escolhidos aleatoriamente e será aplicada uma dinâmica com o mesmo especialista e sobre o mesmo tema, com cada grupo. Um grupo participará da entrevista usando a ferramenta sem a funcionalidade da área onde ficam as perguntas para o entrevistado e o outro grupo participará usando a ferramenta InterVIU com a área onde aparecem as perguntas.

Em pesquisas futuras, é possível que sejam desenvolvidas novas ferramentas para dar suporte a outros tipos de entrevistas. Por exemplo, um mensageiro, onde possam ser realizadas entrevistas de um-pra-um. Ferramentas de vídeo-conferência que sejam usadas para a realização de entrevistas com grupos pequenos. Um fórum que dê suporte a entrevistas, permitindo que as perguntas sejam enviadas de forma assíncrona com grupos muito grandes, etc.

Com o desenvolvimento de outras ferramentas específicas, é possível criar um portal de entrevistas, onde sejam descritos processos diferentes da técnica entrevista e sejam disponibilizados ferramentas para criação de entrevistas. No portal, profissionais podem ter suporte para criação e realização de entrevistas mediadas por computador.

\section{Referências}

Lage, Nilson. Reportagem: teoria e técnica de entrevista e pesquisa jornalística. 2. ed. Rio de Janeiro: Record, 2002.

Medina, Cremilda. Entrevista: O diálogo possível. São Paulo: Ática, 2002.

Minicucci, A. (2001) Técnicas do trabalho de grupo, Atlas, $3^{a}$ ed.

Nunes, R. R. ; Barbosa, C. ; Pimentel, M. . Técnica Entrevista como Dinâmica Educacional. In: XIX Simpósio Brasileiro de Informática na Educação, 2008, Fortaleza. SBIE 2008, 2008.

Pessoa, E. (2002) “Entrevist@: uma ferramenta de bate-papo para entrevistas.” Projeto Final de Bacharelado em Informática. Rio de Janeiro: IM/UFRJ.

Pimentel, M. (2006) CommunicaTEC: Tecnologias de Comunicação para Educação e Colaboração. In: SBSI 2006, 2006, Curitiba, PR. III Simpósio Brasileiro de Sistemas de Informação. Curitiba, PR : SBC.

Pimentel, M., Gerosa, M. A., Filippo, D., Raposo, A., Fuks, H. e Lucena, C.J.P. (2006) Modelo 3C de Colaboração no desenvolvimento de sistemas colaborativos. Anais Simpósio Brasileiro de Sistemas Colaborativos. Natal - RN.

Ugulino, W., Nunes, R. R., Oliveira, C. L., Pimentel, M., Santoro, F.M. (2008) Dos processos de colaboração para as ferramentas: a abordagem de desenvolvimento do projeto CommunicaTEC. Proceeding of XIV Brazilian Symposium on Multimedia and the Web: II Workshop of Business Process Management. 